\title{
Diaminopimelic Acid and Lysine Auxotrophs of Pseudomonas aeruginosa 8602
}

\author{
By CAROLYN E. CLARKSON* AND PAULINE M. MEADOW \\ Department of Biochemistry, University College London, \\ Gower Street, London, $W_{\mathrm{I}} E 6 B T$ \\ (Accepted for publication 22 March 197I)
}

\begin{abstract}
SUMMARY
Lysine auxotrophs have been isolated from Pseudomonas aeruginosa 8602 . Three of the mutants were deficient in diaminopimelate decarboxylase and accumulated meso- and LL-diaminopimelic acid (DAP) but otherwise were indistinguishable from the parent strain. The fourth mutant required lysine for optimal growth, grew slowly on meso- but not LL-DAP, and the DAP which accumulated in large amounts was solely the LL-isomer. This mutant was deficient in diaminopimelate epimerase. No significant differences were detected between its wall composition and that of the parent strain but it was particularly sensitive to carbenicillin.
\end{abstract}

\section{INTRODUCTION}

The role of diaminopimelic acid (DAP) as a key intermediate in the biosynthesis of lysine in bacteria is now well established (see review by Work, 1960). It has also been shown to be present in the mucopeptide component of a number of Gram-positive bacteria and in all the Gram-negative bacteria so far examined (Salton, 1964). Whereas the other dibasic amino acids found in the mucopeptide of Gram-positive bacteria have been shown to exist in the L-configuration, DAP has been found as both LL- and meso-isomers (Hoare \& Work, 1957), although the latter is the most widely distributed. In Gram-negative bacteria, where the mucopeptide makes up a much smaller proportion of the wall, the DAP-isomer present has been thoroughly investigated in only a few species. The meso-isomer has been identified chromatographically in all the Gram-negative bacteria studied and firmly identified in Aerobacter cloacae (Anwar, Roy \& Watson, 1963) and in Escherichia coli (Diringer \& Jusic, 1966). There have been no reports of the occurrence of either the LL- or DD-isomers in walls of Gram-negative bacteria. An opportunity to study the role of DAP in pseudomonads arose from the isolation of lysine auxotrophs, one of which was shown to be deficient in diaminopimelate epimerase (EC 5.I.I.7). This paper reports their growth requirements, wall composition and response to antibiotics known to interfere with wall synthesis.

\section{METHODS}

Organisms and media. The parent strain was Pseudomonas aeruginosa 8602 (Brammar, McFarlane \& Clarke, 1966). It was maintained on slopes containing nutrient broth (Oxoid code no. CM 67; Oxo, London; $25 \mathrm{~g}$. and $10 \mathrm{~g}$. agar/1.). This medium without agar is designated complex medium. The minimal medium contained (g./1.): $\mathrm{K}_{2} \mathrm{HPO}_{4}$, I2.5; $\mathrm{KH}_{2} \mathrm{PO}_{4}, 3 \cdot 8 ;\left(\mathrm{NH}_{4}\right)_{2} \mathrm{SO}_{4}, \mathrm{I} \cdot 0 ; \mathrm{MgSO}_{4} .7 \mathrm{H}_{2} \mathrm{O}$, 0.I ; carbon source, 10; trace element solution, $5 \mathrm{ml}$. (Kelly \& Clarke, I962). Succinate was normally used as carbon source but under

\footnotetext{
* Present address: Research Unit in Radiobiology, Mount Vernon Hospital, Northwood, Middlesex.
} 
some restrictive conditions this induces the lytic phase of the lysogenic phage and it was then replaced by glucose or citrate. L-Lysine (I mM) was added for growth of the mutants unless otherwise stated. Dilution buffer contained (g./1.): $\mathrm{KH}_{2} \mathrm{PO}_{4}, 3 ; \mathrm{Na}_{2} \mathrm{HPO}_{4}, 7 ; \mathrm{NaCl}, 4$; $\mathrm{MgSO}_{4} \cdot 7 \mathrm{H}_{2} \mathrm{O}, 0.2$. Media were sterilized by autoclaving ( $2 \mathrm{I}^{\circ}, 15 \mathrm{~min}$.). All liquid cultures were shaken at $37^{\circ}$.

Isolation of mutants. Lysine auxotrophs were isolated by penicillin enrichment after exposure of the parent strain to a mutagen as follows. The bacteria were grown overnight in $5 \mathrm{ml}$. of complex medium. They were harvested and resuspended in $4 \mathrm{ml}$. citrate buffer (O.I M, pH 6.0). $N$-Methyl- $N^{\prime}$-nitro- $N$-nitrosoguanidine (O.I mg./ml. of citrate buffer) was added and after $40 \mathrm{~min}$. at room temperature the bacteria were harvested and resuspended in $5 \mathrm{ml}$. of dilution buffer. This suspension $(0.25 \mathrm{ml}$.) was used to inoculate $5 \mathrm{ml}$. of minimal medium + succinate and incubated for $2 \mathrm{~h}$. Carbenicillin ( $\mathrm{I} \mathrm{mg.)}$ was then added and incubation continued for $90 \mathrm{~min}$. The bacteria were harvested, resuspended in $5 \mathrm{ml}$. of dilution buffer and $0.1 \mathrm{ml}$. added to $5 \mathrm{ml}$. of minimal medium + succinate + lysine before incubating overnight. The bacteria were spread on agar plates of minimal medium + succinate + lysine $(2 \mu \mathrm{g} . / \mathrm{ml}$.). After incubation for $48 \mathrm{~h}$. pin-point colonies were picked and streaked on plates of minimal medium + succinate with and without lysine to test their lysine requirement.

Growth and inhibition tests. Bacteria from an overnight culture in complex medium were harvested, washed with water, resuspended in water at the same volume and used to inoculate the test cultures (0.0I ml. per $2 \mathrm{ml}$. in test tubes with metal caps). Growth was measured in terms of the extinction at $670 \mathrm{~nm}$.

Minimum inhibitory concentrations of antibiotics (MIC) were determined after $18 \mathrm{~h}$. growth in minimal medium + succinate + lysine to which sterile dilutions of the antibiotics had been added.

To study the effects of antibiotics during growth, antibiotics (in I $\mathrm{ml}$. water) were added to cultures in complex medium ( $100 \mathrm{ml}$./1. flask) which had been inoculated with an overnight subculture ( $10 \mathrm{ml}$. complex medium).

Enzyme assays. The products of diaminopimelate decarboxylase (EC4.I.I.20) and diaminopimelate epimerase activity were detected chromatographically (Work, 1963) in the bacteria after $\mathrm{I} 8 \mathrm{~h}$. growth in minimal medium + succinate + lysine. Quantitative assays were carried out by Dr P. J. White. DAP decarboxylase was measured by the evolution of carbon dioxide from meso-DAP in the Warburg apparatus at $37^{\circ}$ in an atmosphere of nitrogen (White, Kelly, Suffling \& Work, 1964). DAP epimerase activity was measured manometrically by following the evolution of carbon dioxide from LL-DAP in the presence of excess CAP decarboxylase. The activity of each enzyme was expressed in manometric units (White, Lejeune \& Work, 1969).

Accumulation of DAP and ultraviolet-absorbing material. After $18 \mathrm{~h}$. growth in minimal medium + succinate + lysine $(40 \mu \mathrm{g}$. $/ \mathrm{ml}$.) the cultures were harvested and cell-free extracts prepared in a French pressure cell $\left(12,000 \mathrm{lb} / \mathrm{in}^{2}{ }^{2}\right.$ ). The amounts (Work, 1957) and the isomers of DAP (Hoare \& Work, 1955) were determined in the extracts and in the culture-filtrates concentrated 100-fold by rotary evaporation. Extinction of the concentrated culture-filtrate was measured at $260 \mathrm{~nm}$, and expressed in terms of UTP.

Preparation and extraction of walls. After overnight growth in complex medium (1 1./5 l. flask) the bacteria were harvested and washed with saline-citrate solution $\mathrm{pH} 7$ (O. I5 M$\mathrm{NaCl}+0.15 \mathrm{M}$-trisodium citrate). They were resuspended in $20 \mathrm{ml}$. saline-citrate and broken in a French pressure cell ( $\left.12,000 \mathrm{lb} / \mathrm{in}^{2}\right)$. The broken suspension was diluted tenfold with saline-citrate before centrifuging at $3000 \mathrm{~g}$ for $10 \mathrm{~min}$. to remove unbroken bacteria. The supernatant fluid was centrifuged at $14,000 \mathrm{~g}$ for $20 \mathrm{~min}$. to collect the walls. After washing 
the packed walls once more with saline-citrate and six times with water, they were resuspended in water and dialysed against water for $18 \mathrm{~h}$. at $4^{\circ}$ to remove any adhering DAP. The walls were lyophilized in an Edwards High Vacuum freeze drier model $10 \mathbf{P}$ and stored at $4^{\circ}$. Lipopolysaccharide was prepared from the walls by phenol extraction(Fensom \& Gray, I969).

Analytical methods. Amino acid composition of samples hydrolysed with $6 \mathrm{~N}-\mathrm{HCl}$ at $110^{\circ}$ for $18 \mathrm{~h}$. were determined in a Technicon amino acid autoanalyser. Phospholipids and fatty acids were extracted and analysed by thin-layer chromatography and gas-liquid chromatography (Hancock \& Meadow, 1959). Amino sugar and sugar compositions were determined as previously described (Fensom \& Meadow, 1970). Free amino groups in lyophilized walls were measured by the method used by Ghuysen, Tipper \& Strominger (I966) except that the dinitrophenylated derivatives were not separated by thin-layer chromatography but by electrophoresis in pyridine-acetate buffer (pyridine, $10 \%(\mathrm{v} / \mathrm{v})+$ glacial acetic acid, $0.3 \%(\mathrm{v} / \mathrm{v})) \mathrm{pH} 6.4$ for $30 \mathrm{~min}$. at $100 \mathrm{~mA}$ and $2 \mathrm{kV}$. The mono-dinitrophenyl DAP separated well in this system and was eluted from the paper with $0.01 \mathrm{M}-\mathrm{NH}_{4} \mathrm{OH}$ methanol $(\mathrm{I}: \mathrm{I}, \mathrm{v} / \mathrm{v})$. The extinction was measured at $360 \mathrm{~nm}$. in a Unicam SP-800 spectrophotometer in a I cm. cell and results expressed as nmoles mono-DNP-DAP/mg. dry wt of wall.

Isolation and characterization of diaminopimelic acid from walls. Walls were prepared from 1001 . of bacteria grown in minimal medium + glucose + lysine in a fermentation vessel. The freeze-dried walls were hydrolysed under a reflux condenser in $6 \mathrm{~N}-\mathrm{HCl}$ for $\mathrm{I} 8 \mathrm{~h}$. The hydrolysate was filtered, decolorized with activated charcoal and evaporated to dryness in a rotary evaporator. The residue was washed three times with water, dissolved in $2 \mathrm{ml}$. water, applied to a column $(30 \times 5 \mathrm{~cm}$.) of Dowex-50 $(\times 2)$ and then eluted with $\mathrm{I} \cdot 25 \mathrm{~N}-\mathrm{HCl}$ (Meadow \& Work, 1959). The fractions containing DAP were heavily contaminated with cystine, which was removed by peroxide oxidation before separating the DAP by electrophoresis $(90 \mathrm{~mA} / \mathrm{h}, 2 \mathrm{kV})$ in pyridine-acetate buffer followed by chromatography in methanol-water-pyridine-HCl (Hoare \& Work, I955). Di-DNP- derivatives of the isolated DAP and of pure meso- and LL-isomers were prepared (Ghuysen et al. 1966) and their optical rotatory dispersion measured in a Bendix Polarimatic 62 machine in a silica cell $(1 \mathrm{~cm}$. path length).

Chemicals. meso-DAP was separated by fractional crystallization from a mixture of mesoand LL-isomers (Koch-Light Laboratories, Colnbrook, Buckinghamshire) as described by White et al. (1964). The LL-isomer was isolated from the mother liquor by crystallization of its salt with naphthalene-2-sulphonic acid (White et al. 1969). Carbenicillin was obtained from Beecham Research Laboratories. Vancomycin and cycloserine were provided by Eli Lilly \& Co. Ltd, Basingstoke, Hampshire.

\section{RESULTS}

Growth requirements. Four stable lysine auxotrophs designated lys-I, lys-2, lys-3, lys-4 were isolated and their growth requirements studied. None of the mutants grew in less than 6 days in minimal medium with any of the carbon sources tested; addition of I mm-lysine gave optimal growth of all four mutants (Fig. I $a$ ). The rate of growth of the mutants in minimal medium + glucose + lysine was the same as that of the parent strain. For mutants lys-2, lys-3 and lys-4 lysine could not be replaced by any of the other amino acids tested, but lys-I grew slowly with added meso-DAP (1 mM), maximum growth being reached after 3 to 4 days as compared with growth in 8 to Io h. on lysine. When higher concentrations of DAP were used, maximum growth could be achieved in $48 \mathrm{~h}$. (Fig. I $b$ ). LL-DAP was ineffective. 
DAP metabolism. DAP decarboxylase was detected in the parent strain and in the lys-I mutant but $l y s-2,3$, and 4 apparently lack this enzyme (Table I). This was to be expected from the lysine requirements of these three mutants. DAP epimerase, however, was detected only in $l y s-2,3$ and 4 and the parent strain, and not in mutant lys-r. Since this mutant was capable of growing with lysine as sole added amino acid it seemed likely that it had a low level of epimerase activity which could not be detected by the chromatographic method. By using manometric methods Dr P. J. White assayed the enzyme and found that when the
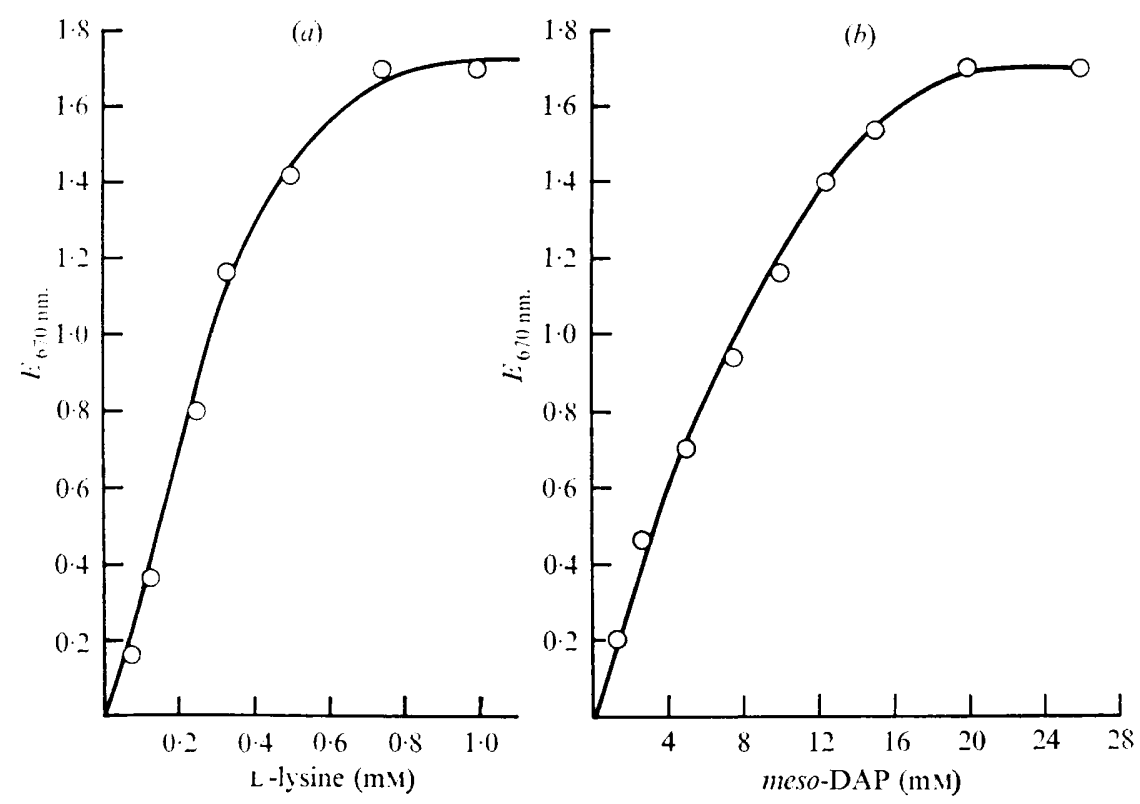

Fig. I. Response of $l y s-I$ to L-lysine $(a)$ and meso-DAP $(b)$. Bacteria were grown in minimal medium with glucose as carbon source for $18 \mathrm{~h}$. (a) and $48 \mathrm{~h}$. (b).

Table I. DAP metabolism of mutants and parent strain of Pseudomonas aeruginosa 8602

DAP decarboxylase and epimerase were detected chromatographically as described in Methods.

\begin{tabular}{|c|c|c|c|c|c|}
\hline & \multicolumn{4}{|c|}{ Mutant } & \multirow{2}{*}{$\begin{array}{c}\text { Parent } \\
\text { strain }\end{array}$} \\
\hline & lys-I & $l y s-2$ & $y y s-3$ & lys-4 & \\
\hline DAP decarboxylase & + & - & - & - & + \\
\hline DAP epimerase & - & + & + & + & + \\
\hline $\begin{array}{l}\text { Isomer of DAP } \\
\text { accumulated in } \\
\text { culture filtrate }\end{array}$ & LL & meso $+\mathrm{LL}$ & $m e s o+\mathrm{LL}$ & meso $+\mathrm{LL}$ & - \\
\hline $\begin{array}{l}\text { Amount of DAP } \\
\text { accumulated (mg./ } \\
\text { 100 ml.) }\end{array}$ & $10 \cdot 0$ & 0.6 & 0.98 & 0.53 & $\circ$ \\
\hline $\begin{array}{l}\text { Ultraviolet-absorbing } \\
\text { material in culture } \\
\text { filtrate (as } \mu \text { moles } \\
\text { UTP/100 ml.) }\end{array}$ & $12 \cdot 2$ & $14 \cdot 7$ & $18 \cdot 0$ & $16 \cdot 1$ & o \\
\hline
\end{tabular}


mutant and wild-type were grown in minimal medium + citrate + lysine there was epimerase activity detectable in both the parent strain (0.010 unit/mg. protein) and the mutant (0.00I unit/mg. protein). The activity of DAP decarboxylase in lys-I (about $0.005 \mathrm{unit} / \mathrm{mg}$. protein) was comparable to that in the parent strain (0.0I unit/mg. protein).

In some species lysine-requiring mutants accumulate DAP and extracellular wall precursors when grown in limiting lysine (Lilly, Clarke \& Meadow, 1963; Knox, Cullen \& Work, 1967). When the pseudomonad mutants were grown under these conditions, DAP and u.v.-absorbing material were found to accumulate in the growth medium, but no amino sugar compounds could be detected either in the growth medium or intracellularly (Table.. 1 ).
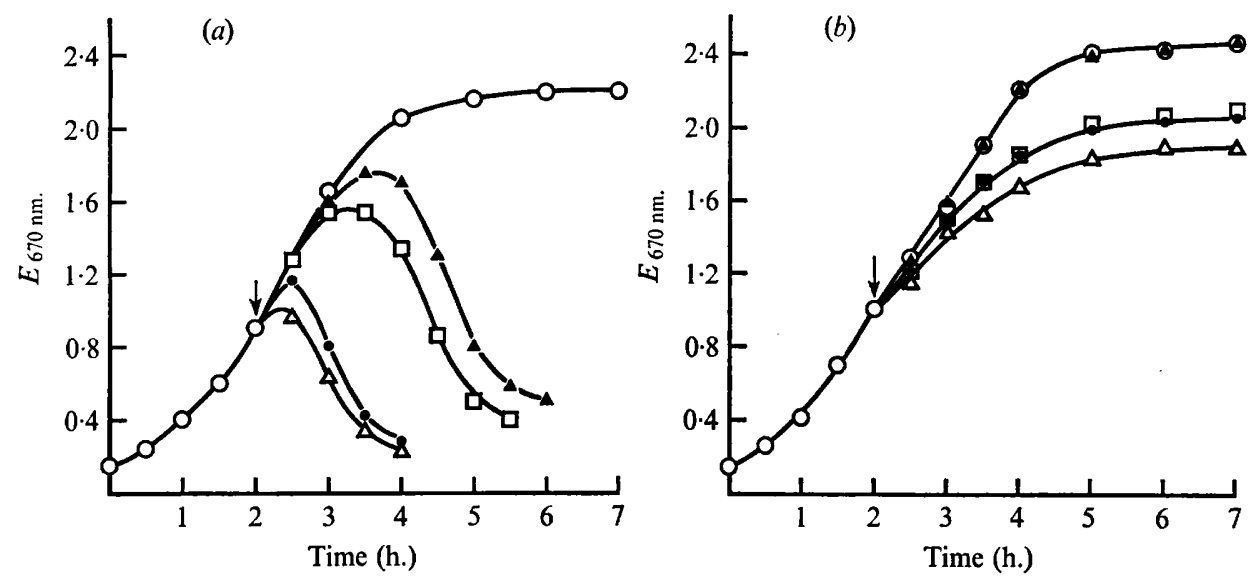

Fig. 2. Effect of carbenicillin on logarithmically growing cultures of lys-I (a) and the parent strain (b). Bacteria were grown in complex medium at $37^{\circ}$ with shaking. At the time indicated by the arrow carbenicillin was added to four of the five flasks. Carbenicillin (final concentration, $\mu \mathrm{g} . / \mathrm{ml}.): \triangle, 300 ; 0,200 ; \square, 100 ; \Delta, 50 ; 0,0$.

Antibiotic sensitivities. The sensitivities of the mutants to various antibiotics known to interfere with wall synthesis were compared with those of the parent strain. There was no detectable difference between the MIC of vancomycin (I50 $\mu \mathrm{g} . / \mathrm{ml}$.) and cycloserine $(500 \mu \mathrm{g} . / \mathrm{ml}$.) for the mutant or the parent strain. However, there was a difference in the MIC of carbenicillin. The MIC apparently depended on inoculum size and a sharp end-point was difficult to determine because of lysis, but the lys-I mutant appeared consistently to be more sensitive (MIC Io $\mu \mathrm{g}$. $/ \mathrm{ml}$.) then the parent strain and the other lysine auxotrophs (MIC $20 \mu \mathrm{g} . / \mathrm{ml}$.). This differential effect of carbenicillin was investigated more thoroughly by adding it to logarithmically growing bacteria (Fig. 2a,b). Lys-I lysed in the presence of carbenicillin $(50 \mu \mathrm{g} . / \mathrm{ml}$.), but even with $300 \mu \mathrm{g}$. $/ \mathrm{ml}$. the parent strain and the other lysinerequiring mutants showed no lysis although their growth rate was slowed. Sucrose (10\%, $\mathrm{w} / \mathrm{v})$ protected the mutant against lysis by carbenicillin. The growth rate in the presence of sucrose was less than in its absence, but even with $200 \mu \mathrm{g}$. carbenicillin/ml. there was no lysis although growth was inhibited. Addition of vancomycin to logarithmically growing cultures caused lysis, but the amount of vancomycin required to produce this effect $(500 \mu \mathrm{g}$.) ml.) was the same for all the mutants and the parent strain.

Wall composition. The greater sensitivity of lys- $I$ to carbenicillin suggested that its wall composition might differ from that of the other mutants and its parent strain. The amino acid composition of walls of lys- $I$ was compared with that of walls of the parent strain 
before and after phenol extraction which removes most of the lipopolysaccharide and lipoprotein components (Table 2 ). No significant differences could be detected. It was possible that the low DAP epimerase activity might cause the mutant to use a different isomer of DAP in its mucopeptide. Paper chromatography showed that both the parent and mutant contained no LL-DAP in their walls, but this method does not distinguish between the mesoand DD-isomers. The di-dinitrophenylated derivatives of the DAP isolated from both batches of walls showed no optical rotation and hence were shown to be derived from pure meso-DAP.

The degree of cross-linking of the DAP in the walls was measured by isolating monodinitrophenyl DAP from walls prepared from the mutant and parent strain at various stages of growth. The number of free amino groups in the logarithmic phase was higher ( $4.3 \mathrm{nmoles}$ DNP-DAP/mg. dry wt walls) than in the stationary phase (3.I nmoles DNPDAP $/ \mathrm{mg}$. dry wt walls) and addition of carbenicillin (100 $\mu \mathrm{g} . / \mathrm{ml} .1 \mathrm{~h}$. before harvesting) increased this further (to $6.4 \mathrm{nmoles} / \mathrm{mg}$. dry wt), but there was no detectable difference between the mutant and parent strain.

Table 2. Amino acid composition of acid hydrolysed walls of lys-I and the parent strain before and after phenol extraction

Walls were prepared and analysed from 81 . of culture grown in complex medium for $18 \mathrm{~h}$. Results are expressed as relative molar proportions with $\mathrm{Glu}=100$.

\begin{tabular}{|c|c|c|c|c|}
\hline \multirow[b]{2}{*}{ Amino acid } & \multicolumn{2}{|c|}{ Isolated walls } & \multicolumn{2}{|c|}{ Phenol-extracted walls } \\
\hline & lys-I & Parent strain & lys-I & Parent strain \\
\hline Cysteic acid & o & $4 \cdot 6$ & 0 & 0 \\
\hline Asp & $66 \cdot 2$ & $82 \cdot 1$ & $69 \cdot 7$ & $68 \cdot 2$ \\
\hline Thr & $*$ & $*$ & $*$ & $*$ \\
\hline Ser & $*$ & $*$ & $36 \cdot 6$ & $41 \cdot 5$ \\
\hline Muramic acid & + & + & + & + \\
\hline Glu & 100 & 100 & 100 & 100 \\
\hline Pro & $34 \cdot 6$ & $36 \cdot 5$ & $34 \cdot 8$ & $4 I \cdot 7$ \\
\hline Gly & $75 \cdot 7$ & $71 \cdot 5$ & $67 \cdot 7$ & 67.4 \\
\hline Ala & $101 \cdot 2$ & 115.5 & IOI 6 & $100 \cdot 4$ \\
\hline Glucosamine & + & + & $23 \cdot 4$ & $25^{\circ} 0$ \\
\hline Val & $47 \cdot 4$ & 53.4 & $59 \cdot 3$ & $59 \cdot 1$ \\
\hline Cys & $4 \cdot 7$ & + & $5 \cdot 1$ & $4 \cdot 8$ \\
\hline Met & $15 \cdot 6$ & 0 & 16.3 & $16 \cdot 8$ \\
\hline DAP & $5 \cdot 4$ & $6 \cdot 2$ & $7 \cdot 8$ & $8 \cdot 4$ \\
\hline Ileu & $34 \cdot 3$ & $34 \cdot 7$ & $32 \cdot 0$ & $48 \cdot 6$ \\
\hline Leu & $75 \cdot 9$ & $65 \cdot 5$ & $76 \cdot 7$ & $72 \cdot 9$ \\
\hline Tyr & $21 \cdot 9$ & $14 \cdot 5$ & 19.3 & $19 \cdot 3$ \\
\hline Phe & $27 \cdot 4$ & $26 \cdot 5$ & $28 \cdot 9$ & $30 \cdot 2$ \\
\hline Unknown $X$ & 15.0 & $12 \cdot 0$ & + & + \\
\hline Orn & $1 \cdot 8$ & $4^{\cdot I}$ & + & + \\
\hline Lys & $44 \cdot 4$ & $45 \cdot 8$ & $45 \cdot 3$ & $45 \cdot 8$ \\
\hline His & $14 \cdot 3$ & $13 \cdot 8$ & $15 \cdot 2$ & 15.0 \\
\hline Arg & $42 \cdot 9$ & $46 \cdot 5$ & $49 \cdot 7$ & $56 \cdot 1$ \\
\hline
\end{tabular}

$+=$ present but not sufficient to estimate; ${ }^{*}=$ present but not separated well enough to estimate; $0=$ absent.

Lipid composition. The total amount of extractable fatty acids in the mutant $(9.6 \%)$ was similar to that in the parent strain $(10.4 \%)$ and analysis by gas-liquid chromatography showed that the individual fatty acids present were comparable both qualitatively and quantitatively to those found in the parent strain, $85 \%$ of the fatty acids being $16: 0$, I $8: 1$ and 19 cyclopropane acids (Hancock \& Meadow, 1969). The major phospholipid component 
in the mutant was phosphatidyl ethanolamine ( 70 to $80 \%$ ) with smaller amounts of phosphatidyl glycerol (Io to I5\%) and bis-phosphatidyl glycerol (5 to $9 \%$ ). This too was indistinguishable from the phospholipid composition of the parent strain.

Lipopolysaccharide composition. Lipopolysaccharide extracted by $45 \%$ phenol, as described in Methods, comprised approximately $30 \%$ of the dry weight of both the parent strain and mutant. Analysis of the isolated lipid A components showed that $70 \%$ was made up of 2-OH I2:0 and 3-OH I2:0 in approximately equal amounts. Although the isolated mutant polysaccharides contained less of the side-chain components glucosamine and mannose than did the parent strain, the major side-chain component rhamnose was unchanged (Table 3).

Table 3. Carbohydrate composition of the isolated lipopolysaccharides from lys- $I$ and the parent strain

\begin{abstract}
Lipopolysaccharide was prepared from 10 1. bacterial cultures grown for $18 \mathrm{~h}$. in minimal medium + citrate. For the mutant lys- $I$ lysine was also present in the medium. The lipopolysaccharide was isolated and analysed as described by Fensom \& Gray (1969).
\end{abstract}

\begin{tabular}{lcc} 
Component & \multicolumn{2}{c}{$\begin{array}{c}\text { Composition }(\%, w / w) \\
\text { lipopolysaccharide from }\end{array}$} \\
\cline { 2 - 3 } & $\begin{array}{c}\text { Parent strain } \\
\text { Rhamnose }\end{array}$ & $8 \cdot 1$ \\
Glucosamine & $3 \cdot 6$ & $7 \cdot 9$ \\
Mannose & $0 \cdot 2$ & $1 \cdot 0$ \\
Glucose & $6 \cdot 4$ & $5 \cdot 4$ \\
Heptose & $6 \cdot 4$ & $5 \cdot 4$ \\
2-Keto-3-deoxyoctonate & $3 \cdot 4$ & $2 \cdot 4$
\end{tabular}

\title{
DISCUSSION
}

The properties of the lysine auxotrophs $l y s-2,3$ and 4 are consistent with their identification as mutants with a single defect in the gene determining DAP decarboxylase. The only differences detected between these mutants and the parent strain were the absence of DAP decarboxylase activity, their obligate requirement for lysine, which was not replaced by DAP, and their accumulation of DAP in the growth medium and intracellularly when grown in lysine-deficient media. The accumulation of DAP by organisms deficient in or lacking DAP decarboxylase has been shown in Escherichia coli (Lilly et al. 1963) and more recently in Staphylococcus aureus (Barnes, Bondi \& Moat, 1969). This accumulation probably results from the mode of control of DAP and lysine metabolism in these organisms. L-Lysine represses the formation of DAP decarboxylase in $E$. coli and in some but not all strains of $S$. aureus (White et al. 1964), and it seems likely that it has the same effect in the pseudomonad (P. J. White, unpublished). Lysine auxotrophs of $E$. coli grown in lysinedeficient media also accumulate lipopolysaccharides related to the bacterial cell wall and, to some extent, the UDP-amino sugar precursors involved in mucopeptide synthesis (Strominger \& Threnn, 1959; Lilly et al. 1963; Knox et al. 1967) as well as DAP. No such compounds accumulated in the pseudomonad mutants deprived of lysine.

The DAP epimerase-deficient mutant lys-I poses some interesting problems. In part its behaviour is similar to that of the only other DAP epimerase-deficient mutant so far described. Barnes et al. (1969) isolated a lysine auxotroph of Staphylococcus aureus designated lys- $F$, in which they could detect no DAP-epimerase activity and which accumulated LLDAP when grown in lysine-deficient media. DAP (I $45 \mu \mathrm{M}$ ) permitted a low level of growth 
in the absence of lysine, but the authors do not report whether DAP could replace lysine completely at higher concentrations or which isomer was used. The slow growth of the pseudomonad mutant $l y s-I$ on meso-DAP (mM) compared with its growth rate on equimolar lysine and its increased growth rate on higher concentrations of meso-DAP suggest that there may be difficulty in transporting this amino acid into the bacterium. In this respect this mutant resembles Escherichia coli, which contains a DAP-permease of activity so low that DAP auxotrophs require the addition of supplementary lysine for optimal growth rate (Davis, 1952; Leive \& Davis, 1965). In pseudomonads the DAP-transport system seems to be even less efficient, since the growth rate of $l y s-I$ in lysine-limited media was unchanged by added DAP (mM).

The surprising feature of the epimerase-deficient mutant is its sensitivity to carbenicillin. This $x$-carboxy benzyl penicillin was developed specifically against the Gram-negative bacteria (Knudsen, Rolinson \& Sutherland, 1967). The minimum inhibitory concentration (20 to $30 \mu \mathrm{g} . / \mathrm{ml}$.) for the parent strain was similar to that reported for other sensitive pseudomonad strains (25 to $50 \mu \mathrm{g}$. $/ \mathrm{ml}$., Knudsen et al. 1967; Bodey \& Terrell, 1968). The mutant was, however, about ten times more sensitive by the tube dilution technique, and addition of carbenicillin to logarithmically growing cultures caused rapid lysis unless the organisms were protected by sucrose. We could not detect any major differences between the isolated walls of the parent strain and the epimerase mutant, either in amino acid, carbohydrate or lipid composition. It is unlikely therefore that the greater sensitivity of the mutant is due to greater accessibility of the antibiotic to its site of action, as is the case in a mutant lacking the side chain of the lipopolysaccharide (Fensom \& Meadow, 1970). Nor is there any evidence that the antibiotic causes any greater inhibition of cross-linking in the mutant walls as compared with those of the parent strain. One possible explanation of the rapid lysis of the mutant lies in its accumulation of large amounts of DAP. Mutant $l y s-I$ accumulated ten times more DAP than the other lysine auxotrophs and none was accumulated by the parent strain. If the DAP transport system is equally slow in both directions it is possible that the accumulation of these amounts of LL-DAP by the mutant increases the internal osmotic pressure until it bursts a wall already weakened by carbenicillin inhibition.

We are grateful to the Medical Research Council for a training grant for C.E.C. and to the Royal Society for the purchase of the gas chromatograph used in this work. We should particularly like to thank Dr Peter White of the University of Sheffield for carrying out the quantitative assays of DAP decarboxylase and DAP epimerase.

\section{REFERENCES}

ANWAR, R. A., Roy, C. \& WATSON, R. W. (1963). Isolation and structure of uridine nucleotide-peptides from Aerobacter cloacae NRC 492. Canadian Journal of Biochemistry and Physiology 41, 1065-1072.

Barnes, I. J., Bondi, A. \& Moat, A. G. (I969). Biochemical characterization of lysine auxotrophs of Staphylococcus aureus. Journal of Bacteriology 99, 169-174.

Bodey, G. P. \& TeRrell, L. M. (1968). In vitro activity of carbenicillin against Gram-negative bacilli. Journal of Bacteriology 95, 1587-1590.

Brammar, W. J., McFarlane, N. F. \& Clarke, P. H. (1966). The uptake of aliphatic amides by Pseudomonas aeruginosa. Journal of General Microbiology 44, 303-309.

DAvis, B. S. (1952). Biosynthetic interrelations of lysine diaminopimelic acid and threonine in mutants of Escherichia coli. Nature, London 169, 534-536.

DiRINGER, H. \& JUSIC, D. (1966). Úber die Bindung der meso- Diaminopimelinsäure in Murein von E. coli. Zeitschrift für Naturforschung 21 $b, 603-604$.

Fensom, A. H. \& GRAY, G. W. (1969). The chemical composition of the lipopoly saccharide of Pseudomonas aeruginosa. Biochemical Journal 114, 185-196. 
Fensom, A. H. \& Meadow, P. M. (1970). Evidence for two regions in the polysaccharide moiety of the lipopolysaccharide of Pseudomonas aeruginosa 8602. Febs Letters 9, 8I-84.

Ghuysen, J. M., TIPPer, D. J. \& Strominger, J. L. (1966). Enzymes that degrade bacterial cell walls. In Methods in Enzymology, vol. 8, pp. 685-699. Edited by E. F. Neufeld \& V. Ginsburg. New York \& London: Academic Press.

Hancock, I. C. \& Meadow, P. M. (1959). The extractable lipids of Pseudomonas aeroginosa. Biochimica et biophysica acta $187,366-379$.

HOARE, D. S. \& WORK, E. (I955). The stereoisomers of $\alpha, \epsilon$-diaminopimelic acid: Their distribution in nature and behaviour towards certain enzyme preparations. Biochemical Journal 61, 562-568.

HOARE, D. S. \& WORK, E. (1957). The stereoisomers of $\alpha, \epsilon$-diaminopimelic acid. 2. Their distribution in the bacterial order Actinomycetales and in certain Eubacteriales. Biochemical Journal 65, 441-447.

Kelly, M. \& Clarke, P. H. (1962). An inducible amidase produced by a strain of Pseudomonas aeruginosa. Journal of General Microbiology 27, 305-316.

Knox, K. W., Cullen, J. \& WoRK, E. (1967). An extracellular lipopolysaccharide-phospholipid-protein complex produced by Escherichia coli grown under lysine-limiting conditions. Biochemical Journal 103, 192-20I.

Knudsen, E. T., Rolinson, G. N. \& SutherLand, R. (1967). Carbenicillin: A new semisynthetic penicillin active against Pseudomonas pyocyanea. British Medical Journal iii, 75-78.

LEIVE, L. \& DAVIS, B. D. (1965). The transport of diaminopimelate and cystine in Escherichia coli. Journal of Biological Chemistry 240, 4362-4369.

Lilly, M. D., ClaRKe, P. H. \& Meadow, P. M. (1963). The accumulation of nucleotides by Escherichia coli strain 26-26. Journal of General Microbiology 32, 103-116.

Meadow, P. M. \& WoRK, E. (1959). Biosynthesis of diaminopimelic acid and lysine in Escherichia coli. I. The incorporation of ${ }^{14} \mathrm{C}$ from various organic precursors into the diaminopimelic acid of a lysinerequiring mutant. Biochemical Journal 72, 396-400.

Salton, M. R. J. (1964). The Bacterial Cell Wall, pp. ro8 to 109. Amsterdam, Holland: Elsevier.

Strominger, J. L. \& ThrenN, R. H. (I959). Accumulation of a uridine nucleotide in Staphylococcus aureus as the consequence of lysine deprivation. Biochimica et biophysica acta 36, 83-92.

White, P. J., KeLLY, B., SUfFLING, A. \& WoRK, E. (1964). Variation of activity of bacterial diaminopimelate decarboxylase under different conditions of growth. Biochemical Journal 91, 600-6I0.

WhITE, P. J., LeJeune, B. \& Work, E. (r969). Assay and properties of diaminopimelate epimerase from Bacillus megaterium. Biochemical Journal $113,589-601$.

WoRK, E. (1957). Reaction of ninhydrin in acid solution with straight chain amino acids containing two amino groups and its application to the estimation of $\alpha, \epsilon$-diaminopimelate. Biochemical Journal 67, $4 \mathrm{I} 6$ 423.

WoRK, E. (1960). The biosynthesis and fate of lysine in bacteria. Colloques Internationaux du Centre National de la Recherche Scientifique 92, 143-169.

Work, E. (1963). $\alpha, \epsilon$-Diaminopimelic acid. In Methods in Enzymology, vol. 6, pp. 624-634. Edited by S. P. Colowick \& N. O. Kaplan. New York \& London: Academic Press. 